\title{
Prediction of bed profile due to complexity of sediment properties in the channel
}

\author{
Mohd Zulkhairi Mat Salleh ${ }^{*}$, Asmawati Che Hasan ${ }^{2}$, Nazri Nasir $^{2}$, Zulkiflee Ibrahim $^{3}$, \\ Zulhilmi Ismail ${ }^{3}$, Mazlin Jumain ${ }^{3}$ \\ ${ }^{1}$ Faculty of Civil Engineering, Universiti Teknologi MARA Pasir Gudang Campus, \\ 81750 Masai, Johor, Malaysia \\ ${ }^{2}$ Faculty of Civil Engineering, Universiti Teknologi MARA Pasir Gudang Campus, \\ 81750 Masai, Johor, Malaysia \\ ${ }^{3}$ Faculty of Civil Engineering, Universiti Teknologi Malaysia, \\ 81310 Johor Bahru, Johor, Malaysia
}

\begin{abstract}
Numerous data on bed profile have been investigated yet the analysis to predict bed profile formation especially related to sediment properties are still insufficient. Objectives of this study to determine significant bed elevation profile pattern formed based on the complexity of sediment properties especially related to sediment size. The investigation is made by carried out a computer simulation of straight channel pattern with the fixed bank and movable sand bed. The study included the various hydraulic characteristics with steady flow rates and sediment properties. The simulations focus on three different sediment sizes with other variables namely channel size, flow rate and bed slope were kept constant. Analysis has included the discussion on a significant difference of bed elevation profile formed along the lateral and longitudinal distance. As a conclusion, the sediment size alone does not significantly change the bed elevation profile as its only gave minor effect to the bed profile changes.
\end{abstract}

* Corresponding author: kayzul00@gmail.com 


\section{Introduction}

The discussion of the influence of sediment properties in the river is yet varied as its very complex for the interpretations. The sediment properties include sediment size, shape, density, the angle of repose and fall velocity. These properties related to each other to make it more complex. The sediment properties also much related to the bed change in the channel. According to Maria Rådoane et al [1], the formation of bed profiled particularly influenced by the sediment size. However, the role of sediment size on the bed formation is still in the discussion since there are so many factors to be considered. Many studies had concentrated on the effect of sediment in the river. According to Mohd Ekhwan Toriman et al [2], the deposition of sand much depends on the grain size of sediment that influences bed load profiles formation in the channel. Frank Engelund and J $\phi r g e n$ Fredsфe [3], also had found that the existence of dunes came from the relationship of sediment in the channel. While other researchers had stated that the sediment could particularly change the rate of bed shear stress depends on the roughness coefficient [4]. The sediment size influenced the rate of bed shear stress thus indirectly influenced the formation of bed profile in the channel.

The bed roughness in the channel can be divided into two categories of grain roughness and form roughness. The grain roughness is defined as a kind of flow resistance that comes from the presence of small and irregularly distributed bed form such as bed materials $[5,6]$. While the form roughness is defined as kind of resistance to flow which occurs due to larger-scale of internal deformation in the flow field imposed by channel bed irregularities such as bedforms and by variations in the planform of the river $[5,6]$. The sediment is acted as a grain roughness of flow resistance influencing the bed changes in the channel. While the wall region area could act as form roughness for flow resistance in the channel. The previous studies have shown that the sediment is one of the contributions for the river changes. The analysis of sediment parameters had been developed in many ways to get the solution to the problem.

The present study focusses on the bed profile formation due to the complexity of sediment, particularly for the sediment size. The objective of the study is to investigate the role of sediment size in the formation of the bed profile in the channel. The analysis also focused on the existent of erosion and deposition process since it can significantly change the bed profile formation. This study is important to verify the behavior of the river in term of its morphology.

\section{Methodology}

The analysis of the study is based on a computer simulation using the NAYS2DH software. The software used to analyze the bed profiled of the channel due to varying sediment size. The Nays2DH widely used as a computational model for simulating horizontal twodimensional (2D) flow, sediment transport, morphological changes of bed and banks of rivers.

\subsection{Description of River Model}

The river model was obtained using Nays2DH software with the dimension of $12 \mathrm{~m} \times 0.5$ $\mathrm{m}$. The straight channel pattern was produced in the simulations. The lateral and longitudinal grid was fixed at $10 \mathrm{~cm}$ each along the channel. The channel bed filled with three different grain sizes of sediment $\left(\mathrm{D}_{50}\right)$ of $0.4 \mathrm{~mm}, 0.5 \mathrm{~mm}$ and $0.6 \mathrm{~mm}$ respectively. The flow of water for each simulation fixed at $0.03 \mathrm{~m}^{3} / \mathrm{s}$. The initial bed shape was flat with 
a rectangular cross-section. The channel slope was set at $1 / 500$. The channel bank is fixed with the movable bed. The value of Manning's Roughness coefficient differs based on the mean grain size used. The roughness coefficient obtained using Cowan (1956) method [7]. The detail of the variables used shown in Table 1.

Table 1. Details of the variables used in the simulation.

\begin{tabular}{|c|c|c|c|c|c|}
\hline Run & $\begin{array}{c}\text { Channel Size } \\
(\mathbf{m})\end{array}$ & $\begin{array}{c}\text { Discharge } \\
\left(\mathbf{m}^{\mathbf{3}} / \mathbf{s}\right)\end{array}$ & $\begin{array}{c}\text { Sediment Size, } \\
\mathbf{D 5 0}(\mathbf{m m})\end{array}$ & $\begin{array}{c}\text { Manning's } \\
\text { Roughness } \\
\text { Coefficient } \\
(\mathbf{m m})\end{array}$ & Slope \\
\hline 1 & $12 \times 0.5$ & 0.03 & 0.4 & 0.02 & 0.002 \\
\hline 2 & $12 \times 0.5$ & 0.03 & 0.5 & 0.022 & 0.002 \\
\hline 3 & $12 \times 0.5$ & 0.03 & 0.6 & 0.023 & 0.002 \\
\hline
\end{tabular}

\subsection{Measurement Method}

The Measurement was made through observation in the simulations. Three stations were measured laterally along the channel. Those stations marked with Section A-A (2 m from upstream), Section B-B (6 m from upstream) and Section C-C (10 m from upstream). The data measured starting at Section A-A of 2 meters from the inlet to make sure that the flow of water kept steady at the measurement points. The bed profile also measured at the centreline, left and right side of the banks. These measurements were made to obtain the significant contribution of wall resistance that affected bed profile in the channel. The bed profile measured laterally and longitudinally. Each simulation set to run for 24 hours duration.
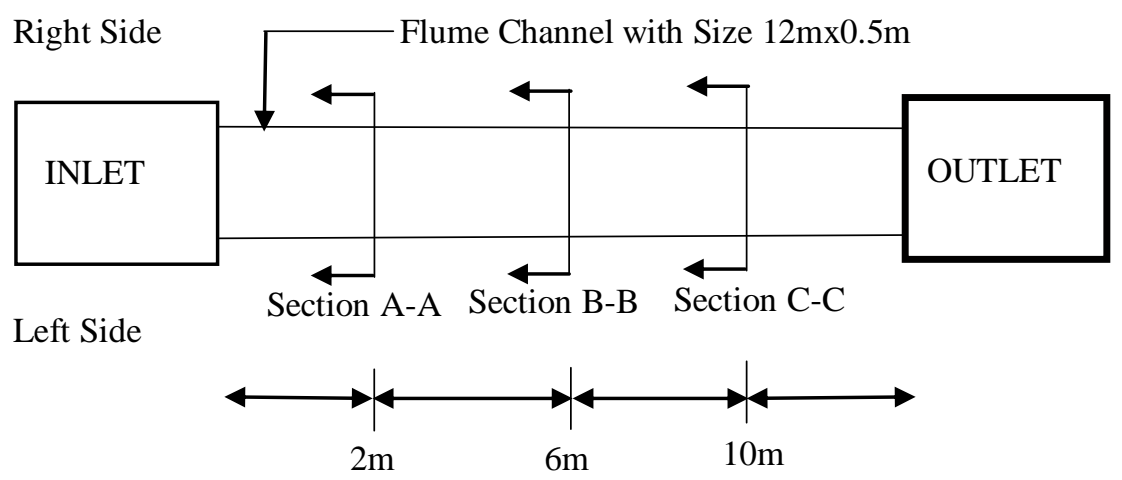

Fig. 1. The channel used in the simulation and locations of measured stations along the channel.

\section{Result and Discussion}

Established in the simulation used, the analysis had obtained to investigate the relationship between various sediments with the formation of the bed profile. Figure 2 to 10 had 
discussed in detail the analysis of the bed profile with related to the different sediment size. The discussions established based on the longitudinal and lateral bed profile.

\subsection{Lateral Analysis of Bed Profile}

In the lateral analysis, it is proven that the erosion process dominants for both sections. Most of the active significant erosion occurred in the near-wall region of the channel. It proved in figure 2, 3 and 4 . The conditions happened as the flow changed into an unsteady condition in this area affected by the flow resistance of the channel bank. The deposition process only takes place at the section B-B as shown in figure 3. This section included a transported area for the channel. The eroded sediment from upstream was transported and deposited in this area. The deposition of sediment happened as the flow of water decreased affected by the flow resistance of bed roughness and wall resistance. The water flow lost its strength of transporting the sediment to make it deposited in the low flow rate regions. The maximum erosion and deposition occurred only within $1 \mathrm{~cm}$ for both sections to show that the small erosion and deposition happened. It was observable in both simulations. These conditions happened as much related to the bed shear stress. Such profiles occurred as the flow used only $0.03 \mathrm{~m}^{3} / \mathrm{s}$ with the steady condition for initial flow. The low flow rate produced smaller bed shear stress in the channel. The bed profiled formed in active condition as only when the bed shear stress is higher along the channel. The use of smaller flowrate produced less erosion and deposition and proved by only $1 \mathrm{~cm}$ maximum rate in the study. The pattern of lateral bed profiled formed almost similar for both sizes of sediments except for sediments size of $0.04 \mathrm{~mm}$ as shown in figure 4 to prove that the sediment size provides a minor contribution to the change of bed profile in the channel.

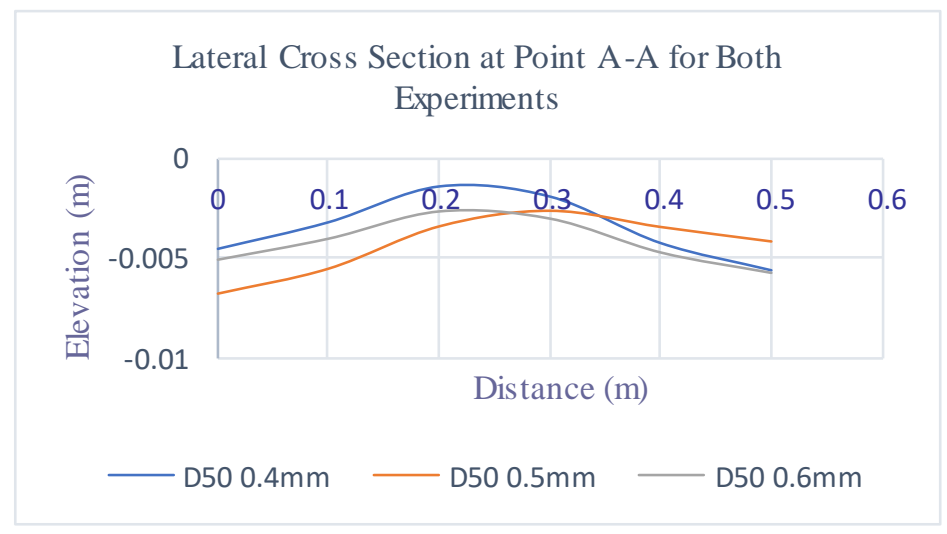

Fig. 2. Lateral Cross Section for Both Experiments at Section A-A 


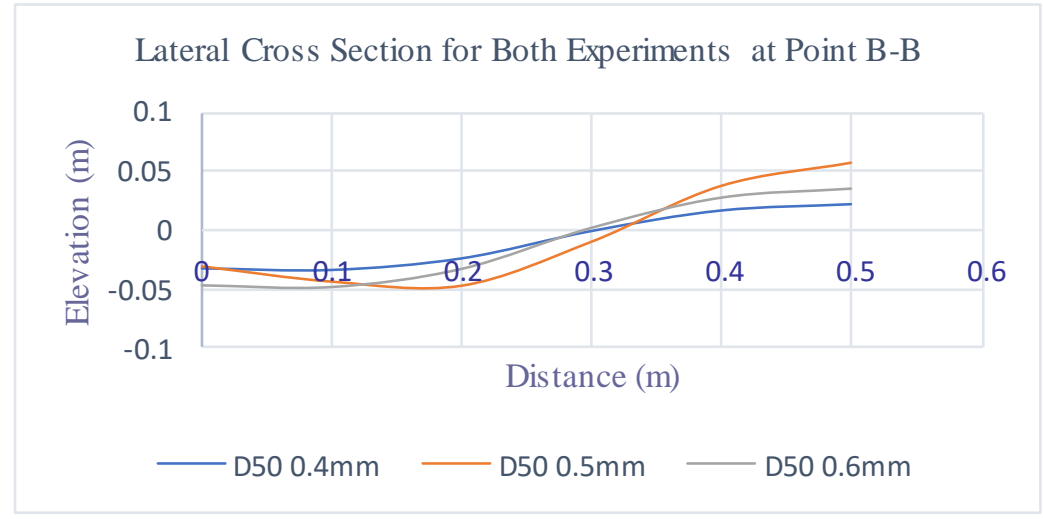

Fig. 3. Lateral Cross Section for Both Experiments at Section B-B

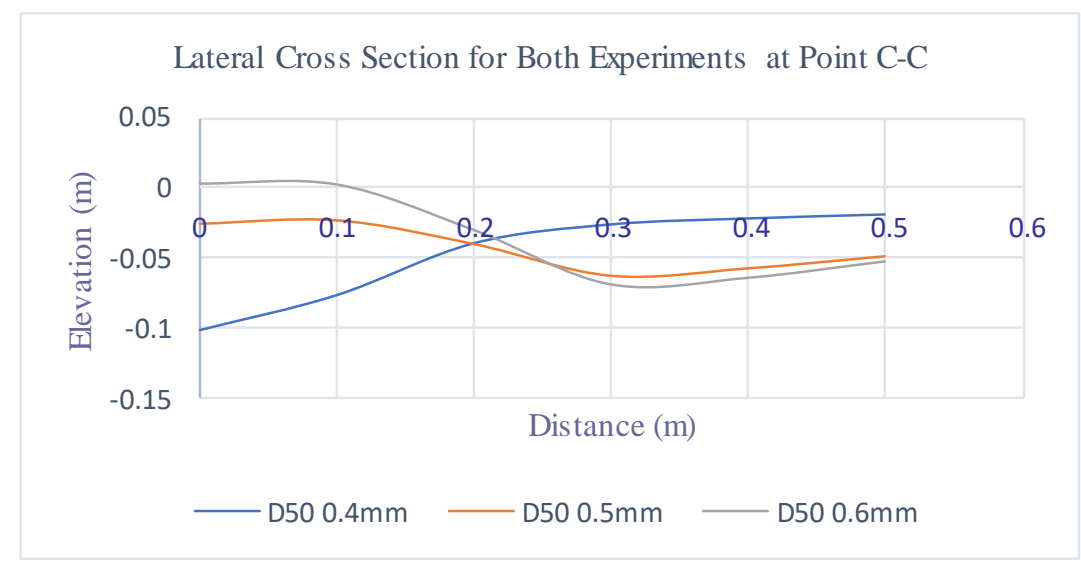

Fig. 4. Lateral Cross Section for Both Experiments at Section C-C

\subsection{Longitudinal Analysis of Bed Profile}

In the longitudinal analysis, the established data obtained based on the bed profiled of three different sediment sizes of $0.04 \mathrm{~mm}, 0.05 \mathrm{~mm}$, and $0.06 \mathrm{~mm}$ respectively. The longitudinal cross-section observed at the centerline, left and right of the channel. There were no changes visible at $1 \mathrm{~m}$ to $5 \mathrm{~m}$ from upstream for both analyses. The changes of bed profiled only occurred started at $6 \mathrm{~m}$ to $12 \mathrm{~m}$ downward. The bed profile particularly changed at the downstream for a straight channel as the erosion and deposition actively occurred in this area. The undulating pattern had been observed starting at $6 \mathrm{~m}$ of bed elevations and the continuous changes occurred throughout the measurement points. The scour started to form at $6 \mathrm{~m}$ of the channel and followed by the dunes. The scour occurred as a product of erosion process and the dunes formed from the deposition process. The sediment from the erosion process acted as the sources for the deposition process at downstream. The bed channel changes in ripples conditions as the erosion and deposition simultaneously take place. Thus, this proved that the erosion and deposition occurred on the channel bed. Its proved in figure 5, 6 and 7. The maximum erosion and deposition occurred at the left side of the channel as 
shown in figure 6. The wall resistance had influenced this condition. The active erosion induced higher deposition as its produced much sources of sediment for the deposition. There were no significant differences in the profiled pattern of channel bed for both simulations to prove that the sediment sizes only give less significant effect to the channel bed as proved by Cowan (1956).

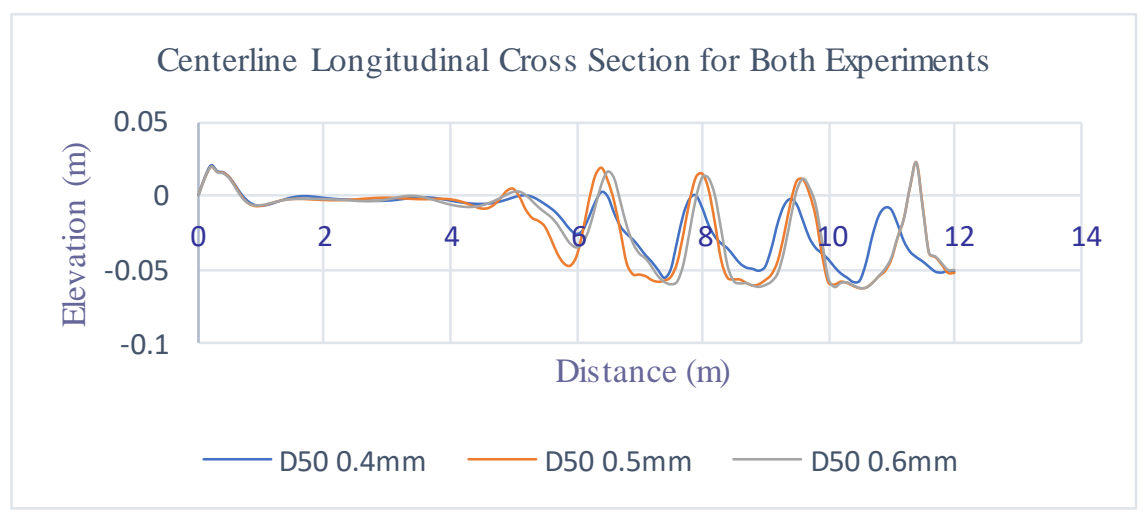

Fig. 5. Centerline Longitudinal Cross Section for Both Experiments

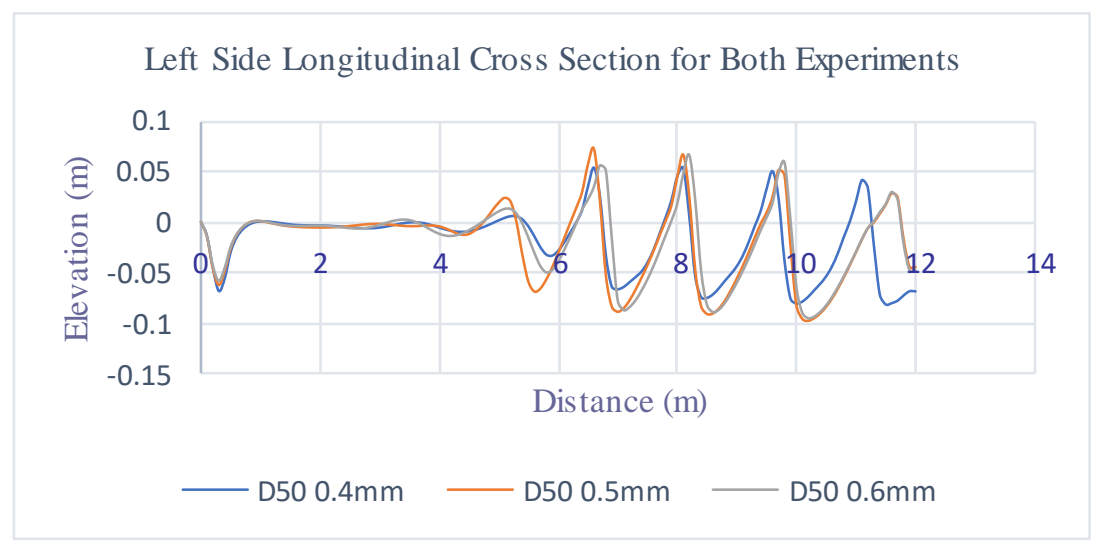

Fig. 6. Left Side Longitudinal Cross Section for Both Experiments 


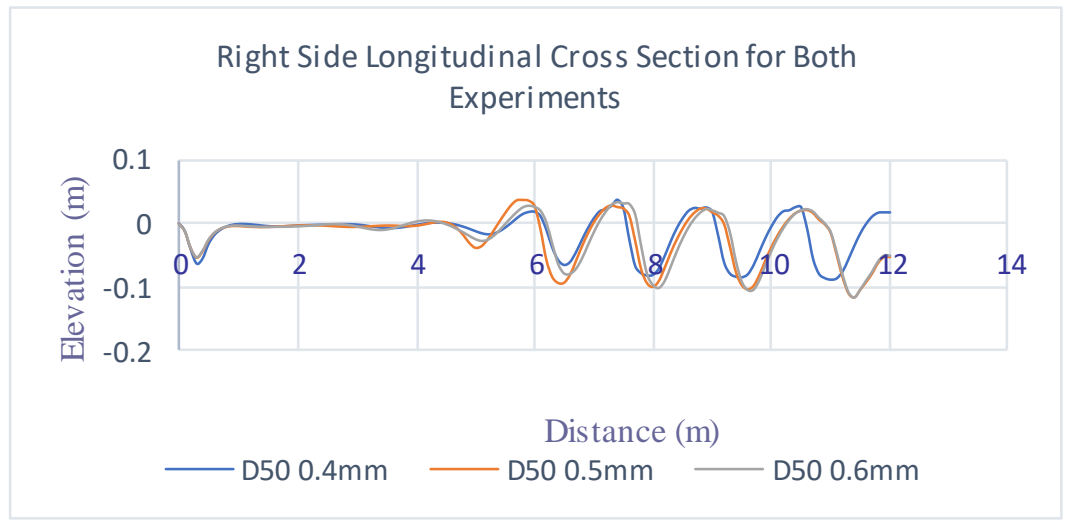

Fig. 7. Right Side Longitudinal Cross Section for Both Experiments

\section{Conclusion}

The study had provided evidence of sediment size role in the formation of bed profiled in the channel. The sediment contributed to the bed changes of the channel as the bed roughness coefficient depends on the sediment size. A quite similar bed profiled pattern formed in the study had proved that the difference sediment size alone does not give large significant effect to the bed profiled formation. However, a minor effect could result in it. The erosion and deposition process was evidenced in the study. Those processes occurred as resulted from the roughness effect of bed and the wall thus directly produced changes to the bed channel. The effect of wall region induced an active erosion and deposition to formed large scour and dunes in the area. In a conclusion, the study had provided enough analysis of the relationship between sediment size and the bed profiled of the channel.

This study is a collaborated research between Universiti Teknologi MARA Pasir Gudang Branch and Universiti Teknologi Malaysia. We would like to acknowledge to all who involved directly and indirectly in this project, especially to UiTM Pasir Gudang and UTM for providing us research facilities and manpower.

\section{References}

1. Maria Rådoane, Nicolae Rådoane, Dan Dumitriu, Crina Miclåu, Earth Surface Processes, and Landforms, (2007).

2. Mohd Ekhwan Toriman, Frankie Marcus Ata, Mohd Khairul Amri Kamarudin, Mushrifah Idris, American Journal of Environmental Science, 9, 292-300, (2013).

3. Frank Engelund and Jørgen Fredsce, Ann. Rev. Fluid Mech. 14, 3-37, (1982).

4. Jerome Peng-Yea Maa, Jae-II Kwon, Kyu-Nam Hwang, Ho-Kyung Ha, Journal of Hydraulic Engineering, 134, (2008).

5. Kadota, A., Asayama, C. and Ndwambi, I. D., River Flow, 907-913, (2016).

6. Mohtar, W. H. M. W., Bassa, S. A. and Porhemmat, M. Sains Malaysiana, 46(5), 685-693, (2017).

7. Cowan, W.L., Agricultural Engineering, 37(7), 473-475, (1956). 